\title{
TRACKING SUSTAINABLE DEVELOPMENT IN POLITICALLY VIOLENT ZONES: NEED fOR FRAMEWORK AND COGNIZANCE- KASHMIR IN CONTEXT
}

\begin{abstract}
Mohmad Aabid ${ }^{1}$, Aadil Farooq ${ }^{2}$
Abstract: As a conceptual framework, Sustainable Development (SD) intends to improve current Well-Being, while preserving or maintaining the basis for future Well-Being (Solow, 1991). In order to measure Sustainable Development various indicators were chosen, among which health has been considered as an important indicator. As a result, we see a huge focus on health in Sustainable Development frameworks. But, the emphasis of frameworks has been only on the physical and epidemiological factors affecting the health. In contrary, in context of a highly political turmoil zone, it is the psychological well-being that is severely affected. This component of health i.e., psychological well-being is neglected to find a significant place in Sustainable Development frameworks. Since, these frameworks are crucial for national level policy making and it is likely that policies formulated on such frameworks may not replicate the same successful results in every context (such as in Armed Conflict). With such understanding in the background, this paper will show the need to focus on mental health in armed conflict situations in Sustainable Development frameworks. This paper will attempt to show how ignoring mental health in armed conflict situations impede development. The need to develop a holistic framework which focuses on mental health in Armed Conflict situations will be highlighted in context of Kashmir.
\end{abstract}

Keywords: Armed Conflict; Sustainable Development Frameworks; PsychologicalWell-Being; Development; Mental Health, Kashmir.

\footnotetext{
${ }^{1}$ Corresponding Author is a research student in department of social work at Jamia Millia Islamia and can be reached at aabidbhat2012@gmail.com

${ }^{2}$ Author is research student in department of community medicine at JNU- New Delhi and can be reached at aadilshah321@gmail.com
} 


\section{UNDERSTANDING SUSTAINABLE DEVELOPMENT}

The earlier conception of development was to increase the growth or to increase the GDP. This conception was more economic in its nature. Hence resources were exploited infinitely to increase the output while no consideration was being paid on whether it affects environment negatively or not. Conventional form of development and Western Developmental Model was propagated. This model believed in "instrumental value" of nature while neglecting its "intrinsic value". They also prioritized the economic growth and assumed consumption as important contributor to human welfare. The "Standard of Living" was considered as an indicator of development. Soon after the $19^{\text {th }}$ century this conception was changed, when focus was laid on "Quality of Life" as a determinant of development. Till the end of $19^{\text {th }}$ century, growth was considered as an end in itself. But with the beginning of social science and humanistic discourse it was emphasized that this notion of development cannot suffice. The "Means" through which this growth was attained was questioned. Paradigm shift was witnessed in development discourse posing the questions of - "Development for Whom? By What Means? At What Cost? It was felt that development as an increase in growth cannot sustain alone, but there is need to have a certain prefix for its sustenance, hence the Sustainable Development came forth.

Sustainability means "to sustain, to maintain, and to continue". Sustainable Development (SD) intends to improve current Well-Being, while preserving or maintaining the basis for future Well-Being (Solow, 1991). Sustainable Development requires mandatorily a human effort to perpetuate the pace of development. To put simply, humans are agents of Sustainable Development. Without taking the human society into consideration, the development discourse is incomplete and likely to fail at any course of time. As a concept, Sustainable Development encompasses in it all the three main dimensions of developmentEconomic, Environmental, and Social dimension (Figure 1).

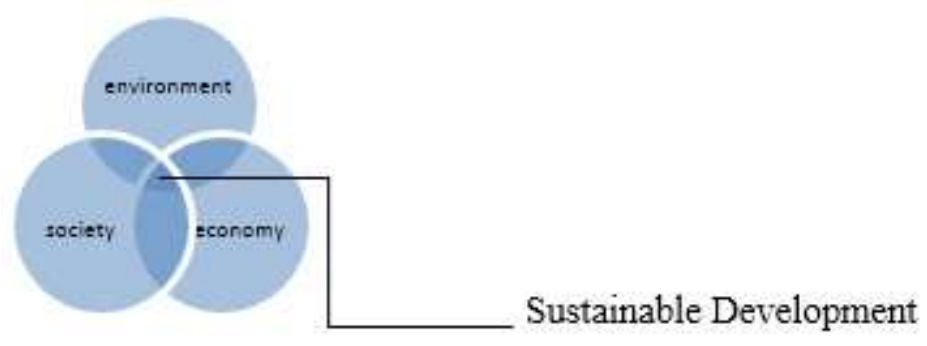

Fig.1 
The figure delineates that the main objective of Sustainable Development is to: a) Protect and Safeguard Environment, b) Maintain Stable Level of Economic Growth, c) and Social Progress that recognizes the needs of everyone (Parker et al., 2003). The concept of Sustainable Development is however very broad and it paves a challenge in understanding what sort of things is included in overlapped section of Sustainability Venn diagram (see Figure 1) in a practical sense. To avoid this confusion various indicators in the form of frameworks are being provided which measure the Sustainable Development.

Among the various frameworks, the "four capital model" framework described by Paul Ekins focuses on the Human capital (Parker et al., 2003) as one the important component of Sustainable Development. It has been acknowledged that increased focus and investment on human capital has been viewed as most essential ingredient in development strategy (Parker et al, 2003). Thus, it can be said that human capital is an indivisible and basic component of Sustainable Development. Since humans are important aspect of Sustainable Development, any negative change to their health standards will ultimately affect the Sustainable Development.

Environment is a major factor affecting the health of the people. A pollutant and disease free setting ensures that people are exposed to hygiene and health and are expected to develop good health. Tacking cognizance of such relationship, Sustainable Development Frameworks indicating the Environmental Indicators were put forward. These frameworks in turn focused only on the physical and epidemiological factors affecting the health while being exposed to environment. While the exposure of armed conflict and mental disturbance on development and sustainability are not being acknowledged.

\section{ANALYZING SUSTAINABLE DEVELOPMENT FRAMEWORKS}

Upon looking the various models of Sustainable Development, doubtlessly health receives a fine position as an indicator of development. Various governmental and Non-Governmental organizations attempted to develop the indicators measuring Sustainable Development with the support of United Nations. Among these organizations, organizations like OECD, UNEP/RIVM, World Resource Institute (WRI), World Bank, SCOPE became potentially involved in determining the indicators to monitor environmental trends. These organizations developed different set of indicators focusing on development. This core set of developed indicators serve as a support for Nation Level Decision- Making (Schirnding, 2002). There are about 130 indicators compiled by commission on Sustainable Development. The indicators have been categorized as: Housing and Urban Indicators, Social Indicators and Health Indicators (Schirnding, 2002). 
With enhanced understanding related to linkage of proposed indicators and the development processes affecting human health, various frameworks came to fore. These frameworks form the base of any developmental policy and used by policy and decision makers. Various frameworks which have been developed are discussed as:

\subsection{Pressure State Response (PSR) Framework}

Developed by OECD, this framework gives a quick description of interactions between socio-ecological components of environment. This framework focuses on the anthropogenic pressures creating the environmental disturbance and the response invoked by the stakeholders against the changing state of environment. This model however has been criticized because of its over simplified representation of socio-ecological interactions and structures and the challenge associated with establishing cause- effect relationships.

\subsection{Pressure- State- Impact- Response (PSIR) Framework}

Developed by European Environmental Agency (EUA, 2003)this framework is modified version of PSR, in which the impact of hazardous environmental exposure on health has been taken into cognizance.

\subsection{DPSEEA- (Driving Forces, Pressures, State, Exposures, Health Effects, and Action) Framework}

Developed by WHO, this framework is refinement of PSR framework wherein the component of "Driving Forces" referring to factors which motivate and push the environmental processes, has been involved. Population growth, technological development, economic development and policy intervention are being considered as the driving forces, generating the "pressure" on environment. Generally, "pressure" is generated by all sort of economic activity. These activities resulted in all sort of chemical pollutants which are outpoured towards land, water and air, changing the "state" (quality) of environment which calls for environmental hazards. The exposure of individual to environmental hazards affects negatively well-being and health causing morbidity, sentinel diseases, death in extreme cases. As a response this invokes "actions" among the stakeholders which can be either at individual level or policy level.

The above frameworks articulate a connection among the various factors influencing the health and environment. These indicators form a crucial link in decision making chain (Briggs et al., 1996).These frameworks have however focused only on the physical and epidemiological factors which are deemed to disturb the health of an individual. On the basis of these indicators the response always focused on technical solution and do not take into account the political 
dimension of these responses (Levrel et al., 2009). These frameworks are considered universal and no doubt, decision making along such lines will bring the positive end result in improving health. However, the loophole in such frameworks is that they may not necessarily bring the expected outcomes in every situation (such as in armed conflict situation). These may prove incompatible in particular situations which are engulfed with volatility and fragility that are political in nature. These frameworks have focused on the "effects" on health such as mortality, morbidity, caused by a huge burden of infectious diseases, cancer, respiratory diseases, waterborne and airborne diseases, malnutrition, lower rate of growth in children, diarrhea, typhoid, occupational and vector borne diseases, etc. The "response" has been provided according to these (physical and epidemiological) indicators. As seen in HEADLAMP (Briggs et al., 1996) project, Millennium Development Goals, various international conventions which focused on to reduction of pollutants into the environment. These responses may prove useful in removing the physical and epidemiological impediments in health but the impact on mental aspect due to political turmoil may not overcome. Hence, the status of physical health may improve on one hand but Mental Health remains debilitated at the other. These may prove viable in developed and conflict free countries, but may not bring the expected end results in conflict torn zone, which are challenging the very much stability on the globe.

\section{ARMED CONFLICT: A CHALLENGE IN THE PATHWAYS OF SUSTAINABLE DEVELOPMENT}

Armed conflict is almost seen in every part of the world. It is "development in reverse" (collier et al., 2003). The cost of the conflict is paid by the civilians in many forms, directly or indirectly related to their health and wellbeing. Gates (Gates et,al., 2012) did a comparative study in Burundi and Burkina Faso to see the developmental consequences of armed conflict. It was seen that both the countries followed a same trajectory of development up to 1990. But, after the civil war in Burundi, it shows a steep decline in growth. It became main impediment in achieving the Millennium Development Goals. The country stands low in universal education, environmental sustainability, and higher in poverty and hunger, child mortality, child morbidity (Gates et al., 2012). Thus armed conflict paves a substantial amount of negative impact on the health and well-being of an individual, directly or indirectly.

Seeing the extent of influence of armed conflict on mental health, it becomes important to include the ignored aspects such as armed conflict and mental health in developmental frameworks. Since these frameworks form a base 
for developmental policies and programs, it needs to be inclusive of all factors affecting the development. Neglecting these indicators will not result in inclusive policies. For example, MDGs where there is no mention of mental health and armed conflict or for that matter the recent SDGs where the mental health has received a minimum significance.

\subsection{Armed Conflict and Mental Health}

War brings with it catastrophic effects on health and well-being. Studies show that besides death, disability, hunger, lack of shelter and livelihood, it lays long term psychological impact on the parties involved (civilians as well as the combatants), thereby reducing capacity of human capital by decreasing their potential and increasing their ineffectiveness. Study by WHO (2001) reflects that $10 \%$ of the population exposed to trauma or war develops serious psychological problems and $10 \%$ develop behavioral changes which affects their effectiveness (Laxaminarayna et al., 2006). Studies done by various researchers on the impact of war on the mental health in different war torn countries has been compiled in the work of Laxaminarayna and Murthy. The studies reveal that the civilian population including children and youth witnessing the traumatic experiences suffer from multitude of psychological disorders, although in varying degrees. The common symptoms found were Depression, Anxiety, PTSD, Social Dysfunctioning etc. The children in Gaza during intifada were observed and found to have developed a high prevalence of nervousness, fears, restlessness, sleep disturbances, nocturnal enuresis, and other psychosomatic symptoms (Hein et al., 1993). Even the war veterans from the developed countries who participated in 'War on Terror' in Afghanistan and Iraq showed a considerable proportion of mental distress after being exposed to violence (Seal, et al. 2007, 2009).

In order to tackle the issues of mental health, the social support networks such as family, relatives, and neighborhood have been identified and thought out as the key drivers. While in situations of armed conflict this very important social support network often gets destroyed. This support network acts as a buffer to minimize the psychological tensions. Social support is being considered as an important link between the health and vulnerability. This view is substantiated by the Elbert et al., (2009) who believe that conflict renders mental impairments and weakens the social support network. This argument is also supported by Barenbaum et al. (2004). Even such support is capable of developing "Resilience" which in turn is believed to help in overcoming the psychological distress. Factors such as socio cultural context, individual capacities, parental support, parental monitoring, family, and community support has proved to be the promoted and protective factors for building resilience. Good parental support and apt parental monitoring, community acceptance and support are believed to raise the self- 
esteem among the victims and minimizing their psychological distress levels (Tol Wietse et al., 2013). Since the armed conflict destroys such social support linkages and acts as a challenge in maintaining good psychological well-being. Prolonged armed conflict exposes people to death and loss, which in turn directly affect the mental health and psychosocial functioning. Besides direst exposure to trauma and weakening of psycho social networks, the "daily stressors" have been considered to play a profound role in mental health (Andrew Rasmussen, Kenneth Miller, 2009).

\subsubsection{Arm-ed Conflict and Mental Health Scenario in Kashmir}

Kashmir is one of the longest standing political issues in south Asia. The issue of Kashmir which has taken different shifts over the period of time has finally turned in an armed conflict since the last few decades now. Ever since, the armed conflict and its subsequent management have started, the Indian state has been engaged in perpetual violation of human rights in Kashmir. Deaths, Enforced Disappearances, torture, custodial killings, arbitrary detentions, rape and harassment, etc. has been a regular phenomenon in Kashmir by the hands of Indian army as stated by the different rights groups. About 8000 persons have been subjected to involuntary disappearance, more than 70000 persons have been killed, and more than 6000 have been buried in unmarked mass graves. The worst lot affected is children, because of being both active and passive participants. About 97000 to 100000 children have become orphans. The number of widows increased drastically from 16000 in 2000 to 32400 in 2008. Being the witness and survivors of such grave violations, this has profoundly affected the mental health of the people in Kashmir.

Living in vicious circle of violations of human rights and atrocities, the mental health patients have increased to an alarming extent in Kashmir. Every household in Kashmir has been a witness to atrocities and violations. As a result, the rush of psychiatric patients to mental hospital in Srinagar had increased from 6 per day in 1990 to 250-300 in 2000 per day (which is the only hospital catering the Kashmir and Ladakh region along with some areas of Jammu region). The total number of patients rose from 1760 in 1990 to 18000 in 1994, to over 50000 in 2003. In 2006, the number of patients had increased to 82000 . According to the recent research report by the MSF, it was revealed that about $45 \%$ of the adults in Kashmir have symptoms of mental distress. About $41 \%$ in the valley are living with depression, with $10 \%$ having the severe depression. Almost $26 \%$ population in the valley has Anxiety related disorders. About $19 \%$ of population is living with PTSD $^{3}$.

${ }^{3}$ Kashmir mental health survey, 2015: A Report Prepared by MSF 
Various studies conducted by organizations and independent researchers had reflected upon the scenario of mental health in Kashmir. Exposure to traumatic events leads a profound impact on the emotional, behavioral, cognitive and physiological functioning of an individual. In a study "characteristics of depression in Kashmir" Amin and Khan (2009) reveals that the prevalence rate of depression is almost $55.72 \%$, particularly in the age group of 15 to 25 years of age followed by 26 to 35 years. However, a difference is seen in the prevalence rate according to gender, age and location. The women are believed to suffer from depression more $(60 \%)$ as compared to men (51\%). Women suffered from higher prevalence of depression in all the age groups, particularly among 26 to 35 years, the productive years of her life.

Besides depression, PTSD has been found common in Kashmiri population with co-morbid psychiatric symptom of depression (Wani et al., 2006). A hospital based study conducted by Margoob et al revealed an increasing trend in depressive disorders in Kashmir (1971: 16\%, 1980: 14\% and in 1989: 32\%). The armed conflict has been attributed as a cause to this dramatic rise in mental health problems. This has not only affected the individual alone, but has lingered the social and community support (Margoob et al., 1993). In addition to this, substance misuse and suicide among youth are on the rise (Syed et al., 2009). The sphere of psychiatric morbidity is very high. About $25 \%$ of people in Kashmir are suffered from life time depressive disorders (Dr. Arshid) (Yaswi et al., 2008). Measuring the variables like neuroticism, anxiety, guilt proneness, self-control among the youth in Kashmir, (Zoya, Yasir, Babita, 2016) in their study concludes that there is increase in level of these variables among the youth who had been exposed to violent episodes as compared to non-exposed group. In a study (Syed Shehna, Chandra Shekhar, undated) the authors attempted to compare the children of Kashmir and Jammu related to their emotional regulation. The study found that there is a significant variation of emotional regulation and impact events scale between the Kashmiri children and children of Jammu.

Not only the people who have been exposed directly suffered, but the indirectly affected group also shows the symptoms of depression. A study by Asima and Aneesa shows that $41 \%$ of the respondents were suffering from mental health problems. This group constitutes mothers who got their sons killed in the conflict (Asima Hassan, Aneesa Shafi, 2013). Various other psychological problems such as sleeping disturbances, nightmares, loss of interest in life, aggressive behavior had been found among the respondents. About $90 \%$ of the respondents had been found fearful and uncertain of coming back home after they left home for work or any other purposes. Psychiatric problems had affected the general health of the patients as well. Problems like hypertension, 
gastroenterological problems, cardiac problems, eating disorders, headache, general weakness had been found (Hassan et al., 2013).

The continuous cycle of violence has resulted in the further deterioration of the conditions in Kashmir. These "Daily stressors" precipitates the issues of mental illness. As a result, the children and youth develop revolutionary and radicalized mindset. The children cannot afford to come out of this mental trauma in persistent conflict situations on their own. They develop high levels of anxiety, fear, and frustration. The height of radicalization can be analyzed from the words of detained boy: "Now I will not pelt stones, I want to wear an explosive laden jacket and blow myself up" (Dilnaz Boga, 2014).

It not only lays its impact on direct victims but also impacts every member of the society irrespective of their age and gender. It makes the dependents of the society more prone to vulnerabilities like incase of Hafiza: Hafiza bano, 52-yearold lady is suffering from "severe reactive depression". She had developed mental illness after his son was picked up by troops from his home.

The nourishment in this kind of environment has lead the psycho social development in such a way that children and youth tend to think on the revolutionary lines. For example, in a case where a child was detained under PSA, his brother resorted to pelt stones. With no rehabilitative programme in place, more and more youth and children tend to develop the feeling of hatred, anger, resentment and revenge.

These children and youth tend to develop away from the prescribed norms of psycho social development of conflict free society. Their thinking and psychology is totally different from the children living in conflict free society. They tend to show a deviance from expected behavior. According to psychologist Dr. Mudasir Firdousi, says that children of such age should be engaged in education and skill development. But unfortunately, during this productive phase of their life they are arrested, which turns them into activists. They tend to develop revolutionary inclinations.

Armed conflicts often aggravate the condition in an area by not only putting pressure on the health of population but also by devastating the avenues through which health care can be achieved and promoted. They destroy the smooth functioning of the health service system and escalate the out of pocket expenditure among the service consumers. In such situations it becomes difficult to sustain development. With such grave situations of mental health in Kashmir, the response of stakeholders has been inadequate. The government has provided a single Psychiatric hospital with disproportionate staff strength catering services to Kashmir, Ladakh and even areas of Banihal and Kishtiwar. The Mental Health Act is only on paper. No inclusive policy for mental illness had been developed. No doubt, the medicines are distributed free of cost at the hospital but the medicines 
are not always available. With growing poverty, the patients are not able to buy the medicines. This develops a relapse in illness.

\subsection{Conflict and Psychological Development: Excerpts from field}

Below are mentioned some representative personal interviews, which shows the feeling of repulsiveness and indifference of people amid persistent armed conflict situation towards the course of development.

In an interview with Arif (name Changed) who is a class $12^{\text {th }}$ student has developed a revolutionary psychology. Normally, the children of his age are expected to be concerned about his studies and his future prospects at this stage of development, shows a variance. In his words, "We do want to study and be successful in our lives, but not the cost of our honor, respect, dignity and freedom. Living in an environment of armed conflict, education etc. no more becomes a priority for you. The only priority becomes survival. Hence we resist for existence. We feel repulsive to any kind of development. Any developmental programme is rejected until this armed conflict is not over".

In the words of Ahmed (name changed), who is class $10^{\text {th }}$ student. For him development is no more a priority. Living amid conflict has changed his priorities. He feels repulsive and indifferent towards the developmental projects and policies:

"We do not need any developmental project until the conflict is resolved. As long as conflict prevails, no developmental project is accepted. How can one think of development when he is deprived of relief of soul and mind and freedom of his choice? The real development is to have a sakoon (relief) of heart". 5

\subsection{Importance of mental health and how its neglect hinders development}

It is evident that the conflicts have a tendency to derail the development, as they put a basic question mark on the sustenance of the human beings. Being exposed to violence people become vulnerable and thus end up with multiple mental ailments. Like any conflict situation, the people in conflict hit Kashmir have become and are being vulnerable to mental illness. Mental illness reduces the will, skillfulness, intellect, and potential to contribute to positive development. Mental illness does not affect individual alone, but impacts families, communities and societies at large. So, maintaining the lower level of mental health will imprint its repercussions on the family, community development and broadly impede societal development.

\footnotetext{
${ }^{4}$ This information has been collected through personal interview with the respondent

${ }^{5}$ Information gathered through interview with the respondent
} 
Since, health has been considered as an important indicator of development. Health is not being defined alone as freedom from physical disease and pain, but the inclusion of social well-being as well (Philip. R. Lee, undated). Well-being can be categorized into two aspects: objective well-being and subjective well-being. Objective well-being is based on observable factors such as richness, health, tangible goods, etc. and subjective well-being is referred to wellbeing which is experienced psychologically. Hence, psychological wellbeing receives an important place in development while it is being neglected in the frameworks to achieve the same.

On the other hand, Mental Health is defined as the state of emotional wellbeing which prompts an individual to recognize their skills, to effectively deal with stressful life situations, to work to produce results and to contribute to society in which they live (Styliandias et al., 2011). Mental health disability incurs huge losses on the development, economically and socially. For example, People with mental health illness have lower rate of employability because of the reasons of absenteeism and early dropout rates. This adds loss to the global economy which has been accessed by certain reports. An estimated loss of $\$ 16 \mathrm{tr}$ has been recorded due to decreased productivities (Styliandias et al., 2011). Similarly, the society with mentally disturbed people cannot be considered a healthy society. With debilitated mental health, people feel repulsive and indifferent to other material and objective well-being. They no more become agents who perpetuate its pace, but in turn become antagonists. Neglecting mental health development hence ultimately put its impact on overall measure of development. Neglecting mental health will not allow us to achieve expected outcome in social development or simply impeding mental health will impede social development. Since development demands to have physical as well as mental needs and resources fulfilled. Overlooking the mental aspect in development will no longer help it to sustain. The sustainability of development therefore lies in taking simultaneously both the physical and mental health into consideration.

\section{Conclusions}

Since, it is clear that health has received a fine position as an important indicator of Sustainable Development. But the frameworks of Sustainable Development which serves as a crucial link in national level decision making and policy prospect, neglect the important aspect of psychological wellbeing. These frameworks have focused primarily on the physical and epidemiological factors impacting the physical health, thus neglecting the mental aspect of health. Replication of these frameworks universally may not bring the same expected results. These frameworks can be found insufficient in particular situations [such as 
political turmoil/armed conflict]. In conflict situations, besides the physical and epidemiological factors, it is the persistent violence, which devastates the mental well-being. These frameworks will do little in reaching towards the burden of mental illnesses in such situations. Such frameworks may try to bring positive results in the dimensions of physical health but these will not address the issue since mental illnesses will remain untouched. Therefore, they may not likely bring the development in holistic sense because of negligence of one of the important aspects of health i.e. mental health. The developmental policy based on these frameworks tend to be more technical in nature. -appropriate to remove the physical and epidemiological impediments in health but insufficient to find compatibility in political turmoil/Armed conflict. The proposed frameworks make us to remain affixed to physical health neglecting the mental health which should not be the case. Like the physical health, mental health is equally important in maintaining well-being, on the whole. Hence, the need is to develop a framework which takes into account the ignored aspects such as armed conflict and mental health. This paper shows such a relationship among the variables of armed conflict and mental health in sustaining development and need to build the frameworks in a more holistic way.

\section{References}

Adshead Fiona, Thorpe Allison, Rutter Jill, 2006: Sustainable Development and Public Health: A National Perspective, The Royal Institute of Public Health

"Alleged Perpetrators": A Report Prepared by JKCCS

Amin. Syed, Khan. A. W, 2009: Life in Conflict: Characteristics of Depression in Kashmir

Bossel Hartmut, 1999: Indicators for Sustainable Development: Theory, Method, Applications, International Institute for Sustainable Development, Canada

Bannon Ian, Collier Paul, 2003: Natural resources and violent conflict, The World Bank

Briggs. D, Corvalan. C, Nurminen. M, 1996: Linkage Methods for Environment and Health Analysis, WHO

Corvalán F Carlos, Kjellström Tord, Smith Kirk, 1999: Health, Environment and Sustainable Development: Identifying Links and Indicators to Promote Action, Epidemiology Resource Inc.

Dale Ann, Newman Lenore, 2008: Social Capital: A Necessary and Sufficient Condition for Sustainable Community Development, Oxford University Press and Community Development Journal

Dolan Paul, Knight Melanie, Metcalfe Robert, Peasgood Pessa, White Mat, (undated): The relationship between well-being and Sustainable Development

D' Acci. Luca, 2011: Measuring well-being and progress. Social Indicators Research, Springer

Gates. Scott, Hegre. Havard, Nygard. Havard, Strand. Havard, 2012: Development Consequences of Armed Conflict, World Development 
Harris M Jonathan, 2000: Basic Principles of Sustainable Development, Global Development and Environment Institute, Tufts University. (working paper series)

Haines A, Kovats R.S, Lendrum Campbell, Corvalan C, 2006: Climate Change and Human Health: Impacts, Vulnerability and Public Health, Journal of the Royal Institute of Public Health.

Hein, Quota, Thabet, Sarraj, 1993: Trauma and Mental Health of Children in Gaza, British Medical Journal

Ivković Frajman Anita, HamMarija, Mijoč Josipa, 2014: Measuring objective well-being and Sustainable Development Management, Journal of Knowledge Management, Economics and Information Technology

Jaipal Rashmi, 2014: Psychological contributions to Sustainable Development, American psychological Association

Kashmir Mental Health Survey-2015: A Report Prepared by MSF

Levrel. Harold, Kerbiriou. Christian, Couvet. Denis, Weber, Jaques, 2009: OECD Pressure-State- ResponseIndicators for Managing Bio Diversity: A Realistic Perspective for a French Bio Sphere Reserve, Biodiversity and Conservation, Springer

Laxaminarayna. Rashmi, Murthy. Srinivasa, 2006: Mental Health Consequences of War: A Brief Review of Research Findings. World Psychiatry

Mitchel G, May A, McDonald A, 1995: PICABUE: a methodological framework for the development of indicators of Sustainable Development, International Journal of Sustainable Development

Martens W.J.M, Slooff R, Jackson E.K, 1997: Climate Change, Human Health and Sustainable Development, Bulletin of World Health Organization

Margoob. M.A, Beg. A.A, Dutta. K.S, 1993: Depressive Disorders in Kashmir; A Changing SocioDemographic and Clinical Profile of Patients over the Past Two Decades. JK Practitioner

Parris M Thomas, Kates W Robert, 2003: Characterizing and measuring Sustainable Development, Annual Review of Environment and Resources

Robert W Kates, Parris M Thomas, Leiserowitz Anthony, 2012: What is Sustainable Development: Goals, Indicators, Values and Practice, Taylor and Francis Group

K. H. Seal, D. Bertenthal, C. R. Sen, C. Marmar, 2007: Bringing the War Back Home Mental Health Disorders Among 103788 US Veterans Returning from Iraq and Afghanistan Seen at Department of Veterans Affairs Facilities. Arch Intern Med, 167(5)

Karen H. Seal, Thomas J. Metzler, Kristian S. Gima, Daniel Bertenthal, Shira Maguen, and Charles R. Marmar. 2008: Trends and Risk Factors for Mental Health Diagnoses Among Iraq and Afghanistan Veterans Using Department of Veterans Affairs Health Care, 2002-2008. Am J Public Health, 99 (9)

Rather. Farooq, 2013: Armed Conflict in J\& K and its Impact on Society: A case study of Kashmir valley, International Journal of Scientific and Research Publications

Review of the Sustainable Development Goals: The Science Perspective, Report published by International Council for Science (2015) 
Schirnding von Yasmin, 2002: Health and Environment Indicators in the context of Sustainable Development, Canadian Journal of Public Health

Thornicroft Graham, Patel Vikram, 2014: Including mental health among the new Sustainable Development goals, BMJ

Transforming our World: The 2030 Agenda for Sustainable Development, Document of United Nations, 2015

Towards integration at last? The Sustainable Development goals as a network of targets, working paper series 2015, DESA

Votruba Nicole, Eaton Julian, Prince Martin, Thornicrof Graham, 2014: The importance of global mental health for the Sustainable Development Goals, Journal of mental health

Wani. Z.A, Margoob. M.A. 2006: Family Study of Adult PTSD Patients in South Asia: Experiences from Kashmir.JK-Practitioner

Yaswi, A., \& Haque, A. 2008: Prevalance of PTSD symptoms and depression and level of coping among the victims of the Kashmir conflict, Journal of Loss and Trauma 